\title{
Co-evolved geomechanical and geochemical rock properties in a contact metamorphosed, shale- hosted watershed
}

ALEXIS NAVARRE-SITCHLER1, RANIA ELDAM POMMER

${ }_{1}$ Colorado School of Mines, Golden CO, asitchle@mines.edu ${ }_{2}$ Colorado School of Mines, Golden CO, reldam@mines.edu

Coupling of physical and chemical processes in watersheds produces observed water quality (stream chemistry) and quantity (discharge) that comprises an important water resource for agricultural purposes, municipal water use, and habitat for aquatic life. Understanding the way water moves through a watershed and the water-rock interactions that produce and sequester solutes in the subsurface is important for generating models that can predict changes in water resources under future climate or land-use conditions. Rock heterogeneity from pore to watershed scale can be an important factor to consider when integrating physical and chemical processes. In this study, chemical and physical rock properties were analyzed for $\sim 130$ samples of variably metamorphosed Mancos Shale from the East River Watershed, Colorado, USA to statistically analyze statistical correlations between rock properties and spatially clustered rock properties across the watershed. Rock properties analyzed include: mineralogy, unconfined compressive strength, porosity and pore size distribution from neutron scattering techniques, gas adsoprtion surface area, carbon isotope ratios, total organic carbon, and cation exchange capacity. These properties statistically cluster into three groups that spatially correlate to proximity to Tertiary igneous intrusions that contact metamorphsed the Mancos Shale. Rock properties also appear to correlate to morphology of the East River channel as measured by sinuosity, river gradient, and radius of curvature. Mineralogy, carbon content, and cation exchange capaity explain $41 \%$ of variation in the watershed ( $\mathrm{PC} 1$ in a principle component analysis). Carbonate minerals, the presence of augite likely related to contact metamorphism, and higher than average carbon content are inversely correlated with framework silicates quartz, mica, and feldspar precentages. An additional $26 \%$ of the variation in sample properties (PC2) is explained by inverse correlation between unconfined compressive strength compared to clay percentages and total surface area. Metamorphism changes pore shape from elongated to spherical and thermally matures the organic carbon. Inorganic and organic carbon isotope signatures in the watershed are statistically the same population, suggesting little influence of mantle $\mathrm{CO}_{2}$ from the instrusive bodies. 